\title{
STERRENBEELDEN \\ ANTROPOMORFE VOORSTELLINGEN VAN DE NAKSATRAS IN INDIA EN CENTRAAL-AZIE
}

Subham, sreyo 'stu, zegt de inscriptie op een doek uit de collectie Aziatische kunst van het Rijksmuseum, hetgeen betekent 'geluk, het ga je goed'. Het is een passende gelukwens voor Pauline Lunsingh Scheurleer bij haar afscheid van het Rijksmuseum. De woorden staan overigens op een Nepalese pata, gedateerd 1515, waarop de god van de maan is te zien, omringd door sterren en planeten (afb. 1). Tijdens een restauratie, uitgevoerd in een atelier in Asperen, kreeg ik de gelegenheid de schildering van heel dichtbij te zien. Zoiets schept een band. Kon ik in 1980 het onder aan deze doek afgebeelde verhaal identificeren als de Sasajataka, het verhaal over een haas die "naar de maan' gaat, en bovendien de hypothese van Pratapaditya Pal bevestigen dat een complete serie sterrenbeelden, naksatras, op deze doek is afgebeeld, ${ }^{1}$ de restauratie opende nog meer perspectieven, en maakte onder andere een hernieuwde lezing van de inscriptie mogelijk. ${ }^{2} \mathrm{Nu}$ is de Amsterdamse doek uitgangspunt voor een bijdrage over antropomorfe voorstellingen van naksatras in India en Centraal-Azië.

\section{'Maanhuizen'}

Voor alle duidelijkheid: naksatras zijn sterrenbeelden, die met de 'loop' van de maan te maken hebben, zoals de 12 tekens van de dierenriem aan de 'loop' van de zon gekoppeld zijn. Men telde aanvankelijk 27, later 28 van deze 'maanhuizen', die overeenkomen met groepen van sterren die de maan 'aandoet' in de loop van een maand. In India, en ook elders, werd bij voorkeur gerekend met de positie van de maan, niet met die van de zon, zowel voor dateringen als voor het vaststellen van de meest geschikte tijd voor een ritueel of voor een militaire expeditie. Astrologen en priesters, in feite al vanaf de Vedische tijd, of misschien nog eerder, ${ }^{3}$ observeerden deze sterrengroepen nauwkeurig en berekenden een gunstig moment om zo'n onderneming te beginnen. Ook het wassen of afnemen van de maan werd in hun overwegingen betrokken: de periode van wassende maan is, wat zij noemden, de lichte helft van de maand, die als uitermate gunstig werd beschouwd voor het ontplooien van activiteiten, terwijl de tijd van afnemende maan, de donkere helft, ongunstig is.

In India werden aan deze sterrenbeelden bijzondere krachten toegeschreven, die doen en laten van de mens beïnvloeden, zoals ook met de stand van planeten en de 12 tekens van de dierenriem terdege rekening werd gehouden. Het is dan ook niet vreemd dat men zich deze sterrengroepen als godheden kon voorstellen, zoals ook met de planeten is gebeurd. ${ }^{4}$ 

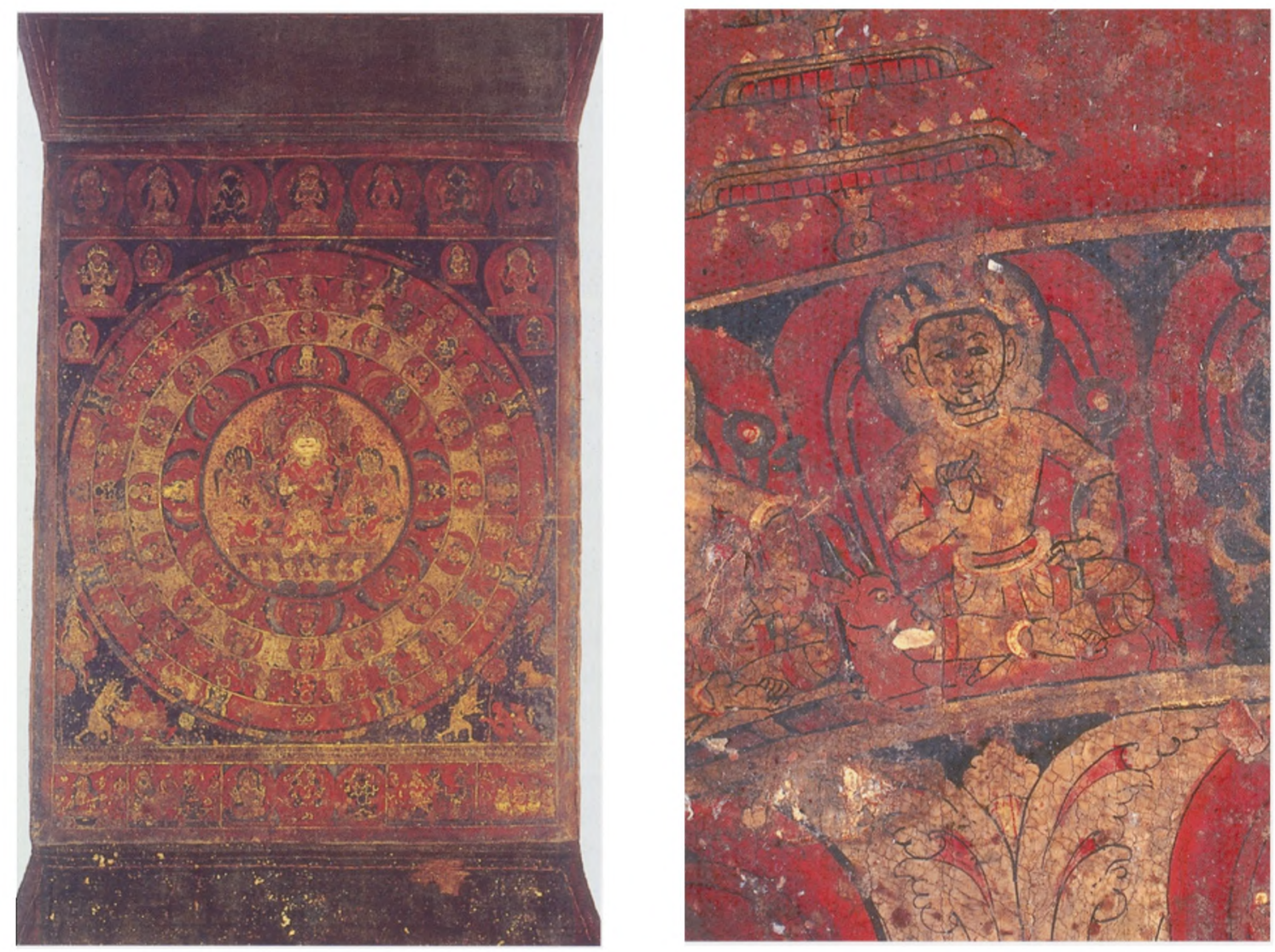

Afbeelding 1 (links)

'Candrapata', doek met schildering van de god van de maan omringd door sterren en

planeten, $74 \times 59 \mathrm{~cm}$., Nepal, 1515,

Rijksmuseum

Amsterdam, collectie

VVVAK, AK-MAK-325

Afbeelding 2

Detail: een van de naksatra's wordt aandacht gevraagd voor relatief vroege antropomorfe voorstellingen in India en Centraal-Azië. Het spoor van de naksatras leidt van Nepal naar Centraal-Azië en China, en eindigt in Noord-India rond de $6^{\mathrm{e}}$ eeuw van onze jaartelling. Dat is een beeldtraditie die zo'n 1000 jaar omspant.

\section{Toyuk}

Het ligt voor de hand om te beginnen met naksatras die met enige zekerheid kunnen worden geïdentificeerd. Deze zijn te vinden in enkele boeddhistische tempels in Toyuk aan de noordelijke route van de fameuze Zijdeweg, en in het meer oostelijk gelegen Khara-Khoto, in de huidige provincie Xinjiang, China. Tempel nr. 6 in Toyuk, gedateerd in de $8^{\text {e }}$ eeuw, bestaat uit een voorhal, gevolgd door een cella van ruim drie meter in het vierkant en ongeveer vijf meter hoog. Voor een bezoeker uit de $8^{\mathfrak{c}}$ eeuw, die deze ruimte betrad en zijn blik omhoog richtte, ontvouwde zich een uitvoerige schildering, aangebracht in de koepel (afb. 3). De koepel is niet hoog, zodat de afzonderlijke figuren duidelijk te zien moeten zijn geweest, en de korte bijschriften in het Indische Brahmi schrift, die bij de buitenste rij figuren zijn aangebracht, eveneens. Wij moeten het doen met de restanten van deze schildering, die overgebracht zijn naar het 'Museum of Central Asian Antiquities' in New Delhi.

De eerste publicaties over deze schildering, en over de naksatras die hier op te zien zijn, dateren uit het begin van de $20^{\mathrm{e}}$ eeuw en zijn van de hand van pioniers als Aurel Stein en Albert Grünwedel. Enige tijd later verscheen een $_{\text {access }}^{\text {3: }}$ 


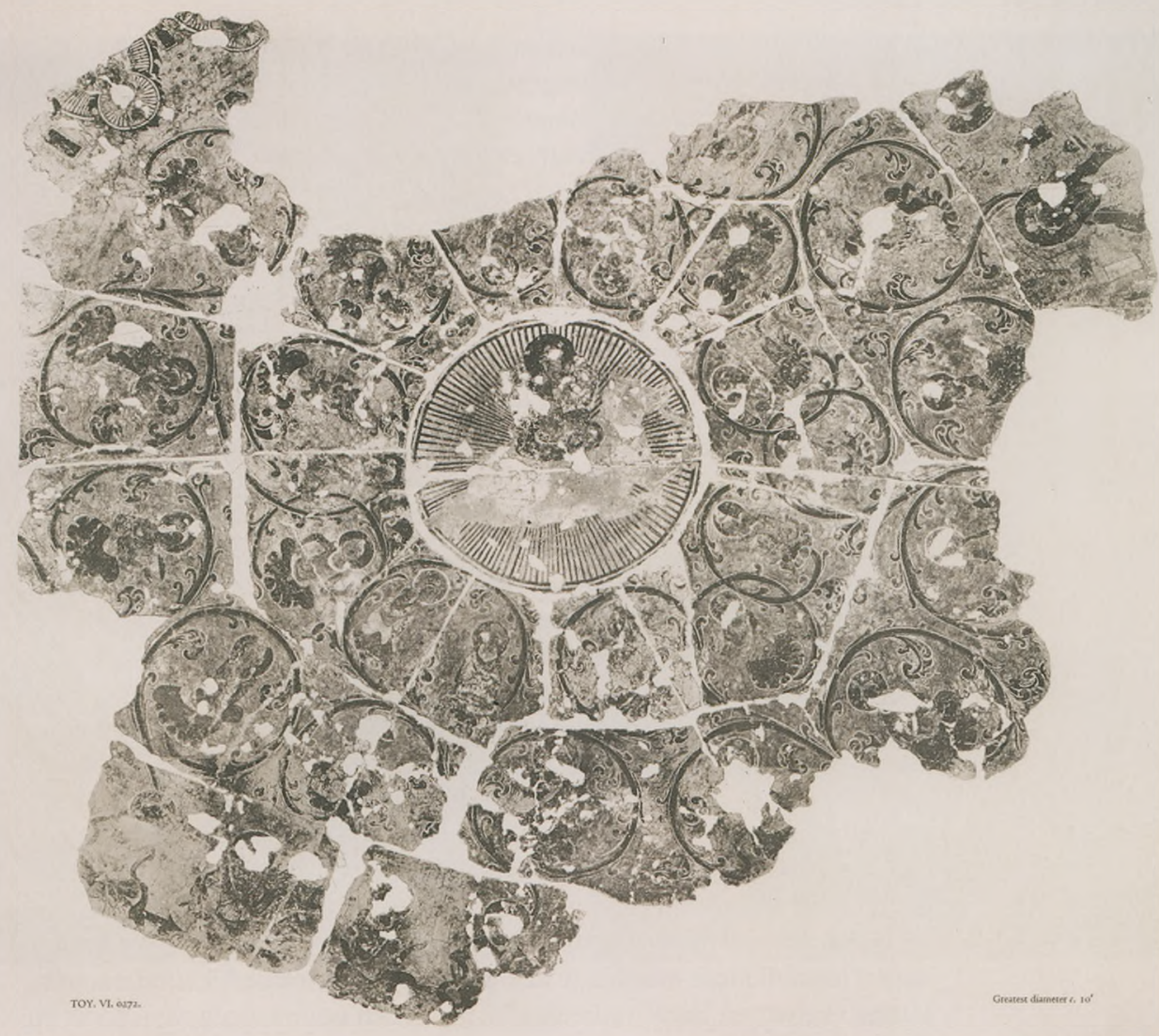

Afbeelding 3 (boven)

Muurschildering in de koepel van grot 6 , Toyuk. Een boeddhistische voorstelling van sterren en planeten rond een niet geïdentificeerde hoofdfiguur, $\tau^{e}$ of $8^{e}$ eeuw. Central Asian Antiquities Museum, New Delhi, no. Toy.VI.0272. Foto Universiteit Leiden, ontleend aan F.H. Andrews, Wall-Paintings from Ancient Shrines in Central Asia, recovered by Sir Aurel Stein, Londen, 1948, pl. X

\section{Afbeelding 4}

Tekening van Andrews op basis van de muurschildering van afb. 3 , gepubliceerd in Andrews 1933 (zie noot 5)

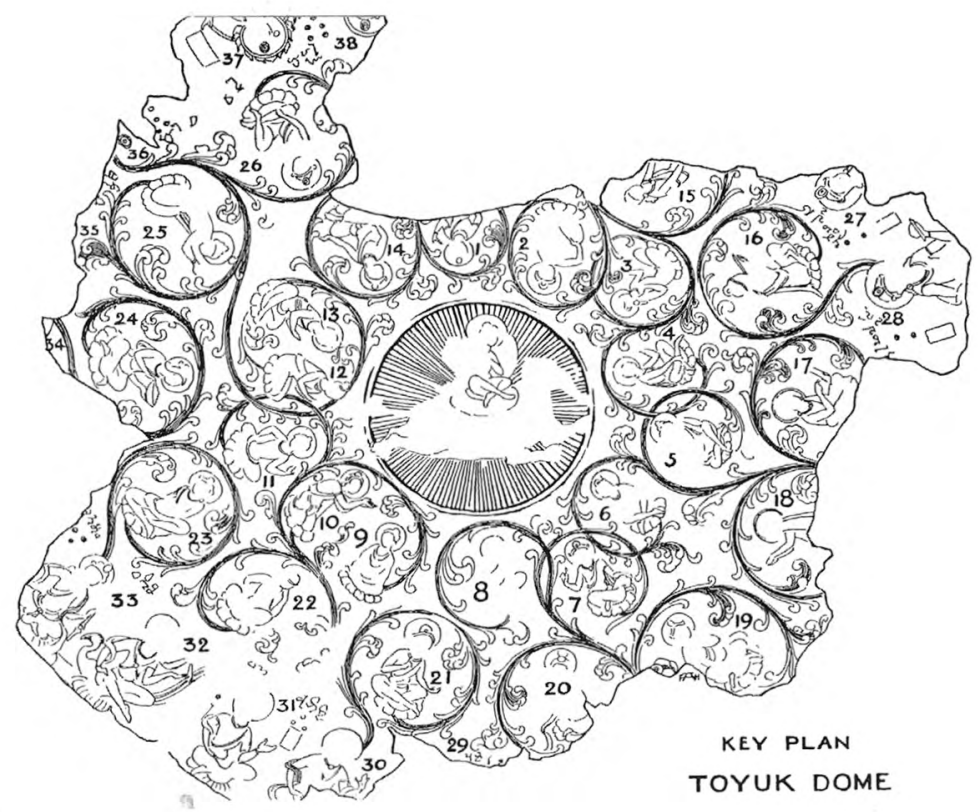


studie van Andrews, die een uiterst gedetailleerde beschrijving geeft en een tekening heeft gemaakt van datgene wat hij toen nog kon zien (afb. 4), en meer recent, in 1992, van P. Banerjea. De laatste besteedt de meeste aandacht aan de naksatras, en interpreteert alle bijgevoegde inscripties. ${ }^{5}$

De voorstelling in Toyuk lijkt enigszins op de schildering op de Nepalese doek, met een hoofdfiguur in het midden en rijen van kleinere figuren om hem heen. De centrale godheid, in een opvallende stralenkrans, is gezeten op iets dat een lotus moet zijn geweest, die weer op een dierfiguur ligt, waarvan nog slechts vage omtrekken te onderscheiden zijn. Identificatie van deze godheid is niet meer mogelijk, hoewel een aantal suggesties is gedaan. Er zijn twee opties: een figuur uit het boeddhistisch pantheon of de god van de maan, die op de Nepalese pata van Amsterdam de centrale plaats inneemt. De nadrukkelijke stralenkrans pleit voor de laatste. Daaromheen volgen ringen van figuren aangebracht in kleine, door sierlijke ranken gevormde medaillons. In de middelste ring ontbreken er een paar. De buitenste ring is er slecht aan toe en bevat figuren die, naar het zich laat aanzien, niet in medaillons zijn weergegeven. Hier zijn nog slechts enkele figuren bewaard gebleven. Vrijwel alle figuren zitten op een lotus, meestal met de benen gekruist, maar soms in een complete lotushouding of op de knieën. Niet alleen de houdingen, ook de gebaren zijn verschillend. Wie de figuren in de twee binnenste ringen precies zijn, is niet meer te achterhalen. Alleen hun aantal is met zekerheid vast te stellen, namelijk 14 in de binnenste en nog eens 14 in de middelste ring. Het is echter ook mogelijk dat we bij de identificatie uit moeten gaan van het aantal medaillons, dat is 12 in de binnenste en oorspronkelijk mogelijk 14 in de middelste ring. Het exacte aantal medaillons is moeilijk te achterhalen. Om gemakkelijker naar hen te kunnen verwijzen heeft Andrews elke figuur een nummer gegeven, zoals op de tekening is te zien.

Verrassend genoeg bevinden zich in de buitenste rij enkele figuren, die met zekerheid kunnen worden geïdentificeerd. De korte inscripties die bij deze figuren zijn aangebracht, blijken hun namen te bevatten, die bovendien soms nog redelijk leesbaar zijn. Duidelijk te lezen zijn onder andere purvaphalguni (nummer 27 op de tekening), uttaraphalguni (nummer 28), en ook rohini (nummer 38). Dat zijn Sanskrit namen van naksatras. Nog verrassender is dat bij deze figuren ook nog drie, vier of vijf ronde punten zijn toegevoegd: vijf punten naast rohini bijvoorbeeld. Het sterrenbeeld rohini telt namelijk vijf sterren. Overigens zijn de naksatras die nog zichtbaar zijn steeds mannelijk voorgesteld en niet vrouwelijk, zoals men vanuit een hindoe-traditie zou verwachten. Eén figuur in de buitenste rij, nummer 32 op de tekening, heeft vier armen, een gekruiste band over zijn bovenlichaam, en als rijdier een pauw. Dat zijn kenmerken van de oorlogsgod Skanda, die ook in CentraalAzië werd vereerd. Maar ook het gesternte sravana wordt afgebeeld met vier armen. Te oordelen naar zijn attribuut, een vajra, zou de figuur naast hem op het eerste gezicht de god Indra kunnen zijn, maar het sterrenbeeld dhanistha heeft een vajra, en deze naam lijkt erboven te staan.

\section{Khara Khoto}

Dat we hier met naksatra-gesternten te maken hebben en dat de ronde punten het aantal sterren aangeven, wordt bevestigd door andere, Soortgelijke 

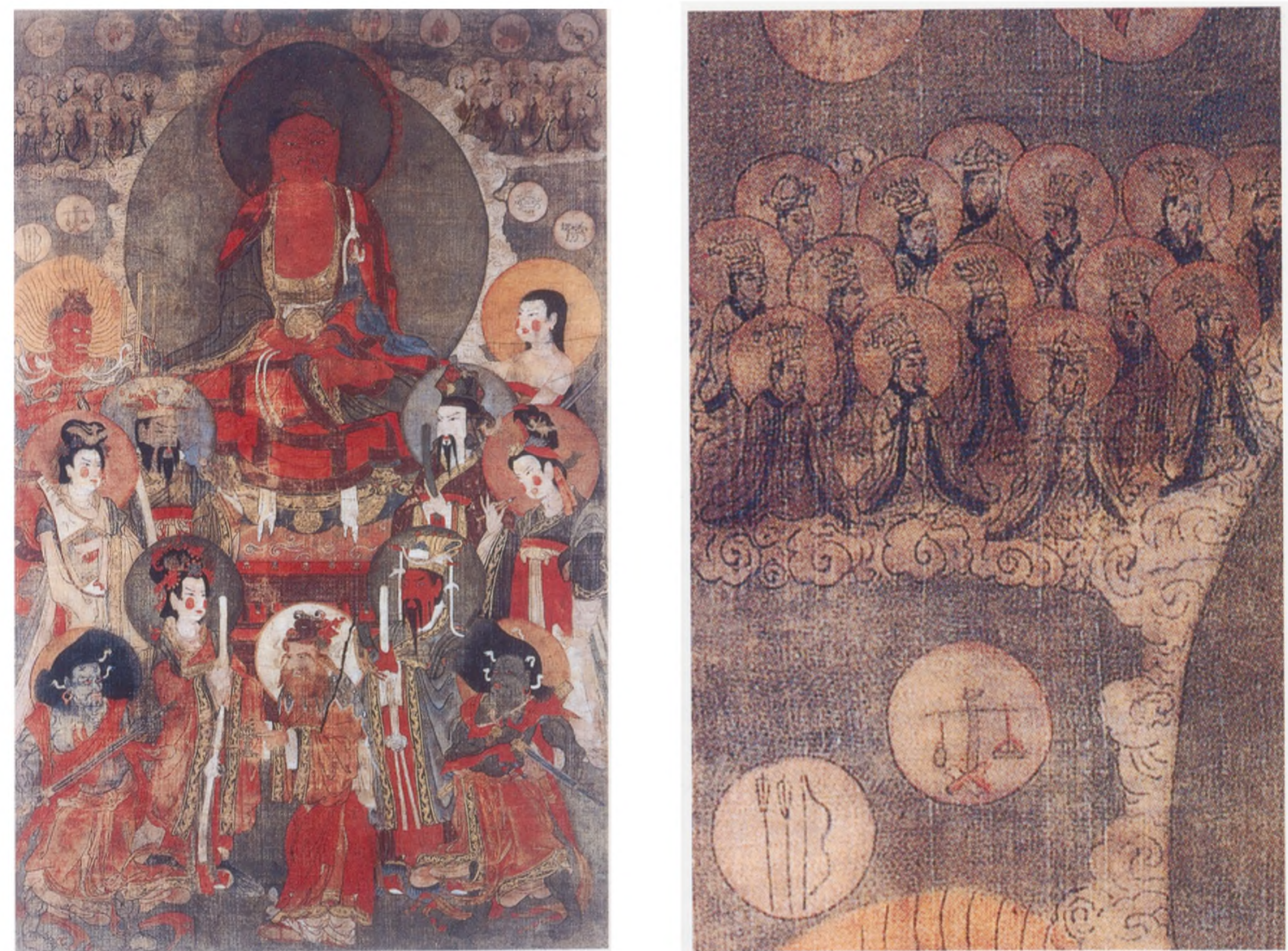

Afbeelding 5

Schildering op zijde, Kara Khoto, Chinees Turkestan, $11^{e}$ eeuw. State Hermitage Museum, St. Peterburg, nr. X-2424.

Foto Universiteit Leiden, ontleend aan Piotrovsky 1993 (zie noot 8)

Afbeelding 6

Detail: een groep naksatras schilderingen in hetzelfde Turfan-gebied, zowel in Toyuk, tempel $3 a$ en $3 b$ als elders. ${ }^{6}$ In een tempel dichtbij het meer oostelijk gelegen Khara Khoto is ook zo'n voorstelling aangetroffen. Albert Grünwedel onderscheidde hier 21 staande figuren, allen voorzien van hun Sanskrit namen, ditmaal in een Uigurisch schrift, en hun Chinese equivalenten. ${ }^{7}$ Naast elke figuur zijn dezelfde gesternten nog eens weergegeven en wel met ronde punten. Hier is bovendien duidelijkheid over het centrale medaillon, althans in de tijd dat Grünwedel deze plaatsen bezocht, en dat is intussen ruim 100 jaar geleden. In het centrale medaillon zijn drie boeddha's afgebeeld, mogelijk de boeddha's van verleden, heden en toekomst.

Naksatra-voorstellingen komen ook voor op een schildering op zijde, eveneens uit Khara- Khoto, uit de $11^{\mathrm{e}}$ eeuw (afb. 5), waar ze - wellicht niet zonder humor - zijn uitgedost als Chinese hoge ambtenaren, gerangschikt aan weerszijden van het hoofd van de boeddha Tejaprabha (afb. 6). Het gezelschap bestaat verder uit de tekens van de dierenriem, en de planeten. De auteur van het gedeelte van de catalogus waarin deze schildering werd gepubliceerd, merkt op dat dit 'protective scrolls' zijn en legt een verband met horoscopen. ${ }^{8}$ Het is een intrigerende opmerking, die in dezelfde lijn ligt als de bevindingen van Angela Howard in haar studie over voorstellingen van de planeten in het Chinese boeddhisme. ${ }^{9} \mathrm{Zij}$ bespreekt en vertaalt een Chineesboeddhistische soetra-tekst met een 'Hora Diagram', waarin rond een hoofdfiguur, hier de bodhisattva Manjusri rijdend op een leeuw, sterren zijn gegroepeerd, namelijk de 28 naksatras, de 12 tekens van de dierenriem, het access 
veld van de negen planeten, en tenslotte zeven figuren die het Zevengesternte - de Grote Beer - moeten voorstellen. Met een 'Hora diagram', een soort sterrenkaart, maakte men een horoscoop.

\section{Manusçript}

Zou een dergelijke betekenis ook van toepassing zijn op de schildering in Toyuk, en op de Nepalese schildering in het Rijksmuseum? Wat Toyuk betreft, zou een manuscript dat is gevonden in Khotan, aan de zuidelijke route van de Zijdeweg, ons duidelijkheid kunnen geven over het praktische gebruik van dergelijke voorstellingen. Het betreft een fragment van een Sanskrit tekst, geschreven in een Indisch schrift dat 'upright Gupta' wordt genoemd, dat mogelijk uit de $7^{\mathrm{e}}$ of $8^{\mathrm{e}}$ eeuw dateert. De tekst heeft de vorm van een instructie: een ziener, genaamd Kharusta, spreekt tot een groep monniken, die met eerbiedig gevouwen handen staan te luisteren, en instrueert hen over verleden, heden en toekomst, over nacht, dag en uur, over maanden en halfmaanden, over sterren en planeten. Het is een astrologische tekst waarin ook naksatras en tekens van de dierenriem worden genoemd, die in een gegeven situatie en in een gegeven combinatie geluk of ongeluk brengen: 'Krttika, Phalguni, Asadha veroorzaken ongeluk in het geval van ruw werk... Purvaphalguni, Purva Asadha en Purva-bhadrapada geven succes in dit geval', zegt de tekst onder andere. ${ }^{10}$

\section{Astrologie}

Is dit de reden dat in de Toyuk-schildering de namen van de naksatras zijn toegevoegd? Stelden de bijschriften de boeddhistische priester in staat hen te herkennen en aan te roepen? Men kan zich voorstellen dat cliënten in de voorhal eerbiedig stonden te luisteren terwijl een monnik in de cella de naksatras selecteerde die op de situatie van zijn cliënt van toepassing waren, in samenhang met de tekens van de dierenriem en de planeten, die overigens zeer waarschijnlijk in de twee binnenste ringen afgebeeld waren. Is een dergelijk verband eveneens aannemelijk voor de voorstelling op de doek in Amsterdam? Deze schildering is vast en zeker ook niet alleen gemaakt om bewonderd te worden, ook al is de schenker zelf een kunstenaar, getuige de inscriptie onder in de doek. Onderin is ook een boeddhistische priester afgebeeld, een vajracarya, die bezig is met een ritueel ten behoeve van zijn opdrachtgevers. Dat ritueel moet iets met astrologie te maken gehad hebben. Bovendien, de naksatras die op deze doek afgebeeld zijn, samen met de planeten en tekens van de dierenriem, komen niet alleen in schilderingen op doek voor, maar ook op houten dakstutten in de - voormalige - boeddhistische Newar kloosters, bijvoorbeeld in de Chusya baha in Kathmandu. Daar staan hun namen eronder, en ook hier zijn ze in het gezelschap van planeten en andere beschermende boeddhistische godheden geplaatst. De naksatras en de andere godheden op de dakstutten worden ook in boeddhistische 'spreukenboeken' genoemd. Het zijn teksten met korte formules, dharanis, die de namen van bijvoorbeeld de naksatras bevatten en die door een priester konden worden gereciteerd bij het vaststellen van een gunstige stand van de sterren. 
Rest nog de beantwoording van de vraag of de naksatras uit het $8^{\mathrm{e}}$-eeuwse Toyuk de vroegst bekende antropomorfe voorstellingen van deze gesternten zijn. Hun aanwezigheid in Centraal-Azië, en de vermelding van hun Indische namen opgetekend in een Indisch schrift, veronderstellen een voorgeschiedenis in India. De zojuist geciteerde tekst uit Khotan is in een Sanskrit dialect geschreven, en is ongetwijfeld op een Indische boeddhistische tekst gebaseerd. Het ligt voor de hand om aan te nemen dat antropomorfe voorstellingen van naksatras in India al voordien bekend waren, mogelijk naar analogie van de antropomorfe voorstellingen van de planeten die voor het eerst in de $5^{\mathrm{e}}$ eeuw als godheden aan het firmament verschenen. Een bekende hindoeïstische Sanskrit tekst uit India, die mogelijk in de $7^{e}$ of $8^{e}$ eeuw werd geschreven, het Visnudharmottara Purana, geeft een summier voorschrift over de manier waarop de naksatras moeten worden afgebeeld, en wel als echtgenoten van de god van de maan: 'De echtgenoten van de maan, naksatras geheten, zijn grote schoonheden, en worden door een ieder vereerd als de dochters van Daksa.' ${ }^{11}$ Het is een aanwijzing, maar ook niet meer, dat in India de naksatras als antropomorfe godheden konden worden beschouwd. Voorbeelden zijn in de beeldende kunst van India echter nog niet gevonden.

\section{Kennis is macht}

De Indiase astroloog-astronoom Varahamihira, die in de $\sigma^{e}$ eeuw in NoordIndia leefde en werkte, kende de naksatras heel goed, evenals de planeten en de tekens van de dierenriem. Hij besteedt in zijn klassieke handboek over sterrenkunde, de Brhat Samhita, uitvoerig aandacht aan de gunstige en ongunstige effecten van deze sterrenbeelden, maar er is geen aanwijzing dat hij hen als antropomorfe godheden beschouwt. Misschien is hij daarvoor teveel een wetenschapper. Hij maakt in een van zijn geschriften de nuchtere opmerking: 'als alleen de gunstige stand van de planeten, de naksatras en andere gesternten de oorzaak zou zijn dat diegene die ten strijde trekt, ook zijn doel bereikt, dan zou de astroloog zelf, en alleen hij, koning zijn.' ${ }^{12}$ 'Kennis is macht', moet ook een $15^{\mathrm{e}}$-eeuwse koning van Nepal met de toepasselijke naam Jyotirmalla - jyotir betekent onder andere astrologie hebben gedacht, toen hij een uitvoerig werk over astrologie schreef, getiteld Siddhisara, hetgeen 'de kern van het succes' betekent. Hij keerde de rollen om. De koning werd astroloog; kennelijk bepaalde hij liever zelf het beste moment om ten strijde te trekken.

\section{Noten}

1. P. Pal, Two Buddhist Paintings from Nepal, Amsterdam, 1967; K.R. van Kooij, 'The Iconography of the Buddhist Wood-Carvings in a Newar Monastety in Kahmandu (Chusya Baha)', Journal of the Nepal Research Centre 3 (1977), pp. 25-82.

2. Aziatische Kunst 25/2 (1995), pp. 27-39.

3. Mogelijk in de Harappa cultuur, ca. 2000 jaar v.Chr., zie A. Parpola, The SkyGarment; a study of the Harappan religion and its relation to the Mesopotamian and later Indian religions (Studia Orientalia 57), Helsinki, 1985.

4. De iconografie van de planeten ontwikkelde zich in de $2^{\mathrm{e}}$ en $3^{\mathrm{e}}$ eeuw van onze jaartelling onder invloed van Grieks-Hellenistische astrologische tradities zię 
D. Pingree, 'Representation of the Planets in Indian Astrology', Indo-Iranian Journal VIIV/4 (1965), pp. 249-267.

5. A. Stein, Innermost Asia; detailed report of explorations in Central Asia, Kansu and Eastern Iran, Oxford, 1928, 4 delen, zie deel 2. Stein meent mijns inziens ten onrechte dat de naksatras zich in de binnenste en middelste ring bevinden; F.H. Andrews, Catalogue of Wall-Paintings from Ancient Shrines in Central Asia and Sistan, recovered by Sir Aurel Stein, Delhi, 1933, pp. 59-63. P. Banerjea, 'Naksatras on the Ceiling of a Buddhist Shrine 'Toyuk", in: Idem, New Light on Central Asian Art and Iconography, New Delhi, 1992, pp. 7-15. Banerjea houdt kennelijk geen rekening met afwijkende spellingen of vormen, en zijn lezingen zijn niet altijd even overtuigend. Zie ook: S. Gaulier, R. Jera-Bezard, M. Maillard, Buddhism in Afghanistan and Central Asia, Leiden, 1976, Deel II, fig. 123.

6. A. Grünwedel, Altbuddhistische Kultstatten in Chinesisch Turkestan, Berlijn, 1912, p. 198.

7. A. Grünwedel, 'Bericht über archäologische Arbeiten in Idikutschari und Umgebung im Winter 1902-1903', Abhandlungen der Philosophisch-Philologischen Klasse der Königlichen Bayerschen Akademie der Wissenschaften, 24. Band, 1. Abteilung, München, 1906, pp. 1-196 en dezelfde, Altbuddhistische Kultstatten in Chinesisch Turkestan, Berlin, 1912, p. 198.

8. K.F. Samosyuk in: M. Piotrovsky (red.), Lost Empires of the Silk Road; Buddhist art from Kara Khoto (X - XIIIth century); the State Hermitage Museum, Milaan, 1993, pp. 228-230. Zie ook van dezelfde auteur, "The Planet Cult in the Tangut State of Xi Xia - The Khara Khoto Collection, State Hermitage Collection, St. Petersburg', Silk Road Art and Archaeology 5 (1997/1998), pp. 353-376.

9. A. Howard, 'Planet Worship; some evidence, mainly textual, in Chinese esoteric Buddhism', Asiatische Studien - Zeitschrift der Schweizerischen Gesellschaft für Asienkunde, 37/2 (1983), pp. 103-119. Met dank aan Dr. G. Mevissen die mij deze aanwijzing gaf.

10. Zie A.F.R. Hoernle, Manuscript Remains of Buddhist Literature found in Eastern Turkestan, Vol. I, Oxford, 1916, pp. 124-125.

11. Het VisnudharmottaraPurana beschrijft de naksatras in boek III, hoofdstuk 68 , vers 6-11.

12. De befaamde astronoom/astroloog schreef deze relativerende zin in een beknopt werk over 'Conjunctie en Militaire Expeditie', getiteld Yogayatra, in hoofdstuk I, vers 5. De tekst is te vinden in H. Kern, Verspreide Geschriften. Eerste Deel, Den Haag, 1913, p. 122. 